IZA DP No. 825

\title{
Gender Wage Gap in Expectations
} and Realizations

Antonio Filippin

Andrea Ichino

July 2003 


\title{
Gender Wage Gap in Expectations and Realizations
}

\author{
Antonio Filippin \\ University of Milan, EUI \\ and IZA Bonn \\ Andrea Ichino \\ EUI, CEPR, CESifo \\ and IZA Bonn
}

Discussion Paper No. 825
July 2003

IZA

P.O. Box 7240

D-53072 Bonn

Germany

Tel.: +49-228-3894-0

Fax: +49-228-3894-210

Email: iza@iza.org

This Discussion Paper is issued within the framework of IZA's research area The Future of Labor. Any opinions expressed here are those of the author(s) and not those of the institute. Research disseminated by IZA may include views on policy, but the institute itself takes no institutional policy positions.

The Institute for the Study of Labor (IZA) in Bonn is a local and virtual international research center and a place of communication between science, politics and business. IZA is an independent, nonprofit limited liability company (Gesellschaft mit beschränkter Haftung) supported by Deutsche Post World Net. The center is associated with the University of Bonn and offers a stimulating research environment through its research networks, research support, and visitors and doctoral programs. IZA engages in (i) original and internationally competitive research in all fields of labor economics, (ii) development of policy concepts, and (iii) dissemination of research results and concepts to the interested public. The current research program deals with (1) mobility and flexibility of labor, (2) internationalization of labor markets, (3) welfare state and labor market, (4) labor markets in transition countries, (5) the future of labor, (6) evaluation of labor market policies and projects and (7) general labor economics.

IZA Discussion Papers often represent preliminary work and are circulated to encourage discussion. Citation of such a paper should account for its provisional character. A revised version may be available on the IZA website (www.iza.org) or directly from the author. 
IZA Discussion Paper No. 825

July 2003

\section{ABSTRACT}

\section{Gender Wage Gap in Expectations and Realizations*}

This paper explores the extent to which the gender wage gap is anticipated by workers' expectations. Data collected among second year students of Bocconi University convey information about their wage expectations. Detailed controls allow a clean matching with a sample of Bocconi graduates providing information about their actual wages. The evidence shows that the gender gap implied by students' expectations one year after graduation is consistent with the gender gap implied by the earnings of their elder counterparts. There is instead a misperception of the gender gap later in the career after graduation because students expect the gender gap to be roughly constant while realizations indicate an increasing gap with experience, particularly for the relatively less skilled worker. There is also evidence that the gender gap at the beginning of a career is particularly high in the most recent cohorts and lower in the previous ones. Finally, our results suggest that the careers of females are characterized by "glass ceilings" in particular at high skill levels, and by "sticky floors" at the opposite end of the skill spectrum.

JEL Classification: J3, J7

Keywords: $\quad$ gender wage gap, expectations

Corresponding author:

Antonio Filippin

Department of Economics

University of Milan

Via Mercalli, 23

20122 Milan

Italy

Email: antonio.filippin@unimi.it

\footnotetext{
*We would like to thank Bocconi University and Giorgio Brunello, Claudio Lucifora and Rudolf WinterEbmer for allowing us to access the data analysed in this paper.
} 


\section{Introduction}

This paper focuses on the correspondence between wage expectations and wage realizations from a gender perspective using data collected among students and graduates of Bocconi University in Milan, Italy. We show that the gender gap implied by students' expectations one year after graduation is consistent with the gender gap implied by the earnings of their elder counterparts who already graduated. There is instead a misperception of the gender gap ten years after graduation because students expect the gender gap to be roughly constant while realizations point toward an increasing gap with experience. The gender gap diminishes but does not disappear when several controls such as family background, place of birth, high school diploma, university program attended, performance at university, civil status and number of children are taken into account. Moreover, quite surprisingly, there is no evidence of a diminishing realized gender gap between subsequent cohorts of Bocconi graduates. On the contrary, the gender gap measured immediately after graduation shows a puzzling upward trend across cohorts.

When we distinguish between different levels of students performance, the best students appear to be characterized by a significant gender gap at the beginning of their careers, which is underestimated in expectations but which remains approximately constant with experience. For the worse students, instead, the gender gap is smaller and correctly anticipated at the beginning of a career, but it increases significantly with their working life and this growth is not expected. These differences between the best and the worse students, suggest that the careers of females are characterized by "glass ceilings" at high skill levels and by "sticky floors" at the opposite end of the skill spectrum.

The paper is organized as follows. Section 2 describes the dataset. Section 3 presents evidence on the reliability of our data while Section 4 shows the econometric evidence and discusses the main results of the paper in connection with the existing literature. Section 5 analyzes whether the perception of the gender wage gap differs according to students' performance. Concluding remarks follow in Section 6.

\section{The dataset}

Students' expectations have been collected circulating an anonymous questionnaire (reported at the end of the paper) among second year Bocconi students. The questionnaire contains questions concerning wage expectations as well as personal information and family background. Such data have been 
merged with Bocconi's administrative data about student's curricula. We obtained access to the same type of administrative information also for a sample of Bocconi graduates, who have been interviewed about their current and past working situation. In this way a clean matching between similar Bocconi students and Bocconi graduates was made possible. Through this matching, we are now able to analyse the expectations of students comparing them with the realizations observed for similar graduates.

\subsection{Students: expected working situation}

The questionnaire concerning students expectations was circulated by Bocconi staff attached to the yearly course evaluation forms. In this way most of the second year students (2497 individuals) received the questionnaire. We got back complete reliable answers for 1154 questionnaires. ${ }^{1}$ Since the questionnaires were anonymous we had to use personal information like gender, date and province of birth to merge them with administrative data. Matching was succesfull for 887 observations. The remaining observations could not be merged either because of the incompleteness of the personal information (e.g. wage expectations, gender and/or date and/or province of birth missing) or because it was not possible to identify a unique counterpart of the questionnaire in the administrative data.

Despite this loss of observations, it is reassuring that descriptive statistics of the merged questionnaires do not significantly differ from those of the questionnaires which could not be merged. The only relevant difference that emerges is that among non-matched questionnaires there are fewer females (42.8 vs. 49.7 percent). Given that one of the purposes of this project is to check whether there are gender differentials in the expected working situation this might be a problem at first sight. However, breaking down matched and non-matched questionnaires across gender, the descriptive statistics of matched and non-matched males are similar. The same is true for the statistics of matched and non-matched females. ${ }^{2}$ So we can safely conclude that the missing information is missing almost randomly.

The questionnaire consists of three parts. The first part concerns the student's expected wage, occupation and sector of employment both one and ten years after graduation. The second part focuses directly on the gender wage gap, asking students about the percentage gender wage differential they expect. In more detail, students are asked to use their expected wage (set equal to one hundred) as a benchmark and to report what is the wage that

\footnotetext{
${ }^{1}$ Bocconi estimates that $75 \%$ of the students were attending the courses.

${ }^{2}$ These statistics are omitted to save space, but are available from the authors.
} 
they think would be earned by a student with the same characteristics as theirs but of the other gender. In what follows, we will refer to this variable as the "self-reported" gender gap, to stress the difference with respect to the gender gap implied by the comparison between the average expected wages of males an females in the sample, collected in the first part of the questionnaire.

Moreover, students who give a "self-reported" gender gap different from zero are asked to choose among some possible explanations for such gap. The proposed explanations are tightly linked with different theories in the discrimination literature (e.g. discriminatory tastes, statistical discrimination, human capital approach).

Finally, the role of the last section, which collects information about personal data and family background, is twofold. On the one hand it makes it possible to merge the questionnaires with the administrative data. On the other hand, it provides a way to check the reliability of the responses to the other parts of the questionnaire, because some answers, like those concerning school performance, can be verified using the administrative data.

\subsection{Students and graduates: administrative data}

As already mentioned, information coming from the questionnaires circulated among students have been merged with Bocconi's administrative records. In addition to information about date of birth, place of birth, place of residence, etc. Bocconi's files keep track of students' high school background (name and place of the high school, type of diploma, grade obtained) and of all the details about student's university career (degree program; specialization; code, date and grade of all the passed exams). For the graduates, information about graduation (date, grade, etc.) is also available.

\subsection{Graduates: working situation}

A sample of Bocconi graduates has also been interviewed, collecting information about their current and past working situation. This dataset contains a large number of information, to be used also in other research projects. Here we use only the variables which are available also for students. It is important to keep in mind that the questionnaire circulated among Bocconi students has been designed to be compatible with the information available for graduates. Therefore, questions have been designed to be as similar as possible to those asked in the survey of graduates. This latter has been conducted by the Research Institute CIRM on behalf of Bocconi University. The target sample included all the 5091 graduates in four years: 1985, 1989, 1993 and 1997. CIRM selected a sample of 2802 students. However, 697 
observations are disregarded because they contain missing values for crucial variables like wages, leading to a final sample of 2105 observations.

\section{$3 \quad$ Reliability of the data}

\subsection{Internal consistency of the expectations dataset}

The dataset on student's expectations offers two ways to estimate the gender gap: first, using the average expected wages computed for the students of the two genders and, second, using the "self-reported" wage gap asked directly by the questionnaire. The comparison between these two different measures of the same concept allow us to check the internal consistency of the expectations dataset.

From descriptive statistics, which we do not report to save space, it emerges that the difference between the expected wage of males and females is greater than the "self-reported" gender gap. There are two possible explanations: either there is a misperception of the expected gender gap or the discrepancy above is due to the fact that while the "self-reported" gender gap refers to identical students of different genders, in the sample males and females have different characteristics. However, if we include in a regression where the expected wage is the dependent variable the "self-reported" gender gap among the observable characteristics that are controlled for, the dummy for gender is no longer statistically significant. Similarly, this dummy is not significant in a regression with the same controls but where the sample has been restricted to students who show a "self-reported" gender gap equal to zero. We interpret these results as evidence in favor of the internal consistency of the dataset. In fact, controlling for several characteristics, differences between the expected wages across genders are not significantly different from the "self-reported" gender gap. ${ }^{3}$

\subsection{Interval measures for wages}

Both students and graduates were asked to report their expected and actual wage choosing between income classes according to the scheme described in Table $1 .^{4}$

\footnotetext{
${ }^{3}$ Results of this analysis are not reported to save space, but are available from the authors.

${ }^{4}$ The reason why Table 1 involves Euro cents is that in the questionnaires amonunts were denominated in Lira, given that questionnaires have been circulated before the Euro became the official currency.
} 
Regressions in the paper are based on income measures obtained assigning a point estimate to every class. To be precise we used the following rule. 75 percent of the upper bound was imputed for the lowest class; the mid point was imputed for each intermediate class and 125 percent of the lower bound was imputed for the highest class. This rule, as any other, is certainly arbitrary but it follows from the plausible assumption that the income distribution is uniform within each intermediate classes, while being skewed toward the upper (lower) bound in the lowest (highest) class.

Robustness checks have been performed on this rule, with particular attention to the implications for gender differentials. Whenever possible, "Interval regressions" have been compared to OLS regressions based on income data constructed with this rule, obtaining very similar results. Note, however, that it was possible to compare these two type of results only when current wages were used. ${ }^{5}$ Yet, the similarity of OLS and Interval regression results when both were feasible is reassuring.

\section{Results}

Table 2 shows the gender wage gap derived from:

1. students' wage expectations at one and ten years after graduation (respectively $t_{0}$ and $\left.t_{1}\right)$;

2. wages earned by the four cohorts of Bocconi graduates. For these cohorts $t_{0}$ stands for the first wage earned, while $t_{1}$ stands for the current (2001) wage. Note, therefore, that for graduates the number of years between $t_{0}$ and $t_{1}$ is not necessarily equal to nine. All the wages are real, having the wages in $t_{0}$ been corrected for the variation of the CPI.

Results in Table 2 are obtained, without controls, from the following basic regression

$$
W_{\tau}^{k}=\alpha^{k}+\beta^{k} F+\varepsilon^{k}
$$

where $\mathrm{W}$ is the logaritm of expected or actual wages at $\tau=t_{0}$ or $\tau=t_{1}, \mathrm{~F}$ is a dummy taking value one for females, $\varepsilon$ is a disturbance term and $k$ is the cohort. For each expected or actual wage measure the coefficient reported

\footnotetext{
${ }^{5}$ In fact, the wage at the time of graduation needs to be corrected for the CPI because in the sample of graduates individuals started working in different years even within the same cohort. This causes the intervals to be different (and overlapping) across individuals. Furthermore, when wage growth is used interval regressions are either useless or not feasible regardless of the correction for the CPI.
} 
in the table is $\beta$, which approximates the percentage gender wage gap: for example -0.097 in the top left part of the table means that wage expectations of females are 9.7 percent lower than wage expectations of males. Note in this table, and in the similar following one, that figures in the $t_{0}$ row are comparable being measures of the gender gap at the beginning of a career. Figures in the $t_{1}$ row are less easily comparable because they are measures of the gender gap at different levels of experience (10 years for students' expectations, 16 years for the 1985 cohort, etc.). However, comparisons within columns are possible as long as it is kept in mind that they give measures of how the gender gap evolves during the working life in different cohorts and for different intervals of experience.

Four facts are immediately evident in Table 2. First, the gender gap expected by students one year after graduation is very similar to the gender gap experimented by the youngest cohort of graduates (1997). Second, the expected gender gap ten years after graduation seems to heavily underestimate the actual gender wage gap. The gap that students expect ten years after graduation is even lower than the gap that those graduated in 1997 experiment only four years after graduation. Third, the actual gender gap immediately after graduation shows a rather intriguing upward trend across subsequent cohorts: this gap is three times larger for the 1997 cohort than for the 1985 cohort. Fourth, both the actual and the expected gender gap increase with labor market experience, but the former seems to increase more.

How does the picture change when controls are included? Table 3 displays the percentage gender wage gap when several characteristics, like family background, place of birth, high school diploma, university program attended, performance at university, civil status and number of children are added to equation 1. The magnitude of the gender gap decreases in most of the cases when controls are included. This is not surprising given the important role played in particular by the civil status and the number of children in explaining the different achievement of males and females in the labor market. However, there is a remarkable exception: the youngest cohort. Although it is intuitive that the younger the cohort the smaller the importance of civil status and number of children as controls, it is striking that for those who graduated in 1997 the gender wage gap is even higher when controls are included. Moreover, the upward trend across cohorts in the gender gap immediately after graduation is still present when controls are included, which is a result worth particular attention.

As far as expectations are concerned, the expected gender gap one year after graduation is roughly correct even when individual characteristics are controlled for. Similarly, the inclusion of controls does not alter the finding that students heavily underestimate the expected gender gap ten years after 
graduation. Even when controls are included the gap that students expect ten years after graduation is lower than the gap that those graduated in 1997 experiment only four years after graduation.

As we said, the figures in the $t_{1}$ row are not directly comparable across columns because the time from first job is different for every cohort. Table 4 gets rid of the problem using the annual growth of expected and actual wages as dependent variable. More specifically, the basic estimated equation is

$$
\frac{\Delta W^{k}}{t_{1}-t_{0}}=\delta^{k}+\gamma^{k} F+\eta^{k}
$$

where, for every cohort $k, \Delta W^{k}$ is the difference of the logaritm of expected or actual wages between $t_{1}$ and $t_{0}$ and $t_{1}-t_{0}$ is measured in years without rounding. For each expected or actual wage measure, the coefficient reported in the table is $\gamma$, which approximates the gender gap in the yearly growth of wages. The first row of the table reports the uncontrolled estimates, while the second row reports results obtained controlling for observable characteristics like family background, place of birth, high school diploma, university program attended, performance at university, civil status and number of children. For example -0.036 in the bottom right part of the table means that within the cohort of those who graduated in 1997 wages of females grew $3.6 \%$ less than wages of males for every year once controls are included. Table 4 confirms that students do not guess correctly the growth over time of the gender gap. In fact, they do not expect the gender gap to increase significantly, while this is an undisputable fact observable in the wage realizations of graduates.

Summarizing the findings of this section, a first important result is that in our data there is no evidence of a decreasing gender gap over time, i.e. across subsequent cohorts of Bocconi graduates, at the beginning of a career. On the contrary, our evidence points toward an increase of the gender gap in recent years, and in particular for the 1993 and 1997 cohorts.

This result is striking because several recent studies indicate that the gender wage gap has been narrowing since the '70s in most industrialized countries (see for example Blau and Kahn, 1996 and 1997). Specifically for the US, Datta Gupta, Oaxaca and Smith (2001) show a clear decline of the gender wage gap during the 1980s. As far as the United Kingdom is concerned, Blundell, Gosling, Ichimura and Meghir (2002) show that gender wage differentials have fallen for younger highly educated workers between 1978 and 1998. Similarly, Fitzenberger and Wunderlich (2002) find that the gender wage gap for full-time employed workers decreased considerably during the period 1975-95, particularly in the lower part of the wage distribution. Also in Italy the gender gap has been estimated to be narrowing by Flabbi 
(1997) who reports that gender differentials decreased from about $30 \%$ in 1977 to less than $20 \%$ in 1995 . Only Scandinavian countries do not display a similar pattern, as reported by Datta Gupta, Oaxaca and Smith (2001), but in these countries the gender wage gap was already very small and still is among the lowest in the world.

Moreover, evidence of a narrowing gender gap between subsequent cohorts is somehow in line with the predictions of the most representative theoretical contributions within the discrimination literature. For example, both the discriminatory taste approach (Becker, 1957) and the statistical discrimination model (Arrow, 1973) imply that gender differentials should not survive in the long run. A gender wage gap could persist in the long run in the presence of self-confirming expectations, as suggested by Filippin (2002). But even in this case there would be no reason to expect an increasing gap. Hence, it is rather puzzling to find such a pattern in the data analysed in this paper.

We can think of only one plausible reason explaining the difference of our results with respect to the literature. The increasing gender wage gap displayed in our data could be a consequence of the fading effects of the cost of living adjustment called Scala Mobile which prevailed in Italy during the '80s and which was abolished in 1992. As explained, for example, in Erickson and Ichino (1994) the design of this adjustment scheme implied a strong compressionary effect on wage differentials of all kinds and in particular on the gender wage gap. The abolition of the Scala Mobile is likely to have allowed an expansion of wage differentials which had been previously artificially compressed.

A second important result of this section is that the gender wage gap is increasing in the first part of the working life. In the literature, a few longitudinal studies provide evidence about the time profile of the gender gap within cohorts. Loprest (1992) finds an 11 percent gender wage gap at hiring within a sample of US young workers of all education levels during the period 1978-83. This gap increases in the first years after hiring and then decreases later during the working life. Light and Ureta (1995) present similar evidence. Kunze (2002) studies the evolution of the gender wage gap within the early stages of careers in Germany. She finds a gender gap of approximately 25 percent for the entry wages of skilled workers trained in vocational schools, but in contrast with the above studies, this gap remains roughly constant during the first eight years after hiring.

A third important result is that students' expectations appear to internalize correctly the existence of a gender gap at the beginning of the career, but fail to capture that such a gap is increasing during the working life. We are aware of only one paper to which this result can be compared, i.e. the paper by Brunello, Lucifora and Winter-Ebmer (2001) who collected a dataset 
containing information about wage expectations of more than 6000 European college students, although they do not have information on wage realizations and they are not intrested in a gender perspective. The authors kindly gave us access to summary statistics of their data from which we could analyse wage expectations by gender. Focussing on the countries where at least 500 observations are available, data suggest the existence of large differences in expectations across countries. The expected gender gap one year after graduation ranges from $9.2 \%$ in Switzerland to $18.7 \%$ in Germany, with Italy and Portugal situated in the middle with a gap of $12.6 \%$ and $16 \%$ respectively. As far as Italy is concerned, their figure differs from ours $(9.7 \%$ in Table 2) but it should be noticed that their sample of Italian students does not include Bocconi University. The cross country differences are less evident when looking at the expected gender gap ten years after graduation. In this case the gap is very similar in Germany and Switzerland (23.3\% and 23.8\%, respectively) while it is slightly higher in Portugal (26.5\%) and Italy (28.3\%). The corresponding figure in our dataset is $13.9 \%$, which indicates that Bocconi students have expectations about the shape of the gender gap during the working life that singnificantly differ from the expectations of other Italian students.

\section{$5 \quad$ Wage expectations and realizations at dif- ferent levels of educational performance}

In order to deepen our analysis of the relationship between wage expectations and wage realizations, in this section we stratify the sample of students and graduates according to their educational performance. Two slightly different stratification procedures have been used for graduates and students.

Using administrative data on the entire population of Bocconi graduates (i.e. not just the graduates interviewed by CIRM) the average grade that separates the top $25 \%$ and the bottom $25 \%$ of the population is used to define the best and the worse performing students. This is done separately for each cohort, since grades are likely to be comparable only within cohorts (see Table 5).

As far as students are concerned, using again population data from administrative records, the top and bottom $25 \%$ thresholds are identified according to a performance variable that summarizes how many exams have been passed during the first year, weighted according to their difficulty and the grade obtained (see Table 6).

Table 7 shows the frequencies of top and bottom performers in our sam- 
ples of graduates and students, using the thresholds defined above for the respective populations. If the samples corresponded exactly to the populations these frequencies should always be equal to $25 \%$, but this is clearly not the case. In particular, they are slightly smaller for the top group of graduates and this might be due to the fact that top graduates are more likely to earn higher wages and, for this reason, to be under-represented in the sample since they refused to answer the income question in the CIRM questionnaire. As far as students are concerned the frequency in the top group is almost 10 points higher than $25 \%$, which may be due to the fact that students not attending classes are more likely to be worse performers and did not receive the questionnaire. ${ }^{6}$

On the basis of the stratification described above we have replicated the analysis of the previous section separately for top, intermediate and bottom students, in order to see whether the comparison between wage expectations and wage realizations differs according to educational performance. The analysis is performed pooling together the four cohorts of graduates because the sample size was not large enough to allow for the distinction between performance levels within each cohort separately. However, we include years since graduation into the regressions to control for experience.

Results obtained controlling for observable characteristics are presented in Table 8 for the gender gap measured immediately after graduation and in Table 9 for the yearly growth of this gap.

The first interesting fact emerging from these tables is that top students clearly understimate the gender gap at the beginning of a career $\left(t_{0}\right)$, while the guess of intermediate and bottom students is more accurate. This result hints at the possibility that top performing students may start their working career under the presumption that the human capital acquired in school is going to be the main determinant of success in the labor marker, while reality is instead different.

A second striking set of facts is offered by the comparison between graduates in the two tables. In the top performance group we see the largest gender gap at the beginning of the career (see Table 8). However, the growth of the gender gap along the working life is larger in the intermediate and bottom performance group (see Table 9 ).

These results suggest the possibility of different patterns of job assignment between males and females at different stages of a career and at different levels of the occupational hierarchy. For example, in the case of the top graduates

\footnotetext{
${ }^{6}$ Remember that the students' questionnaires were attached to the evaluation forms of some courses. Therefore, our students sample has been drawn from the population of students still attending courses at the end of the term.
} 
wage differences, possibly due to different job assignments, seem to emerge immediately after graduation and to persist more or less constantly along the career. A different pattern characterizes instead the worse graduates. Here the evidence suggests that not only wages differ already at the beginning of the career, but also that the difference increases along the working life. As a result, the gender wage gap increases with experience. Following Booth, Francesconi and Frank (1998), this evidence is consistent with the existence of "glass ceilings" for highly skilled female graduates who are excluded since the very beginning of their carears from the same wage prospects offered to males of similar ability. At the same time, our evidence suggests that at the opposite end of the skill spectrum unskilled females experience "sticky floors" which prevent them from enjoying during their careers the same wage growth of their male counterparts. 


\section{Conclusions}

The evidence presented in this paper points towards some interesting findings. We show that the gender gap implied by students' expectations one year after graduation is consistent with the gender gap observed in the actual earnings of their older counterparts who already graduated. There is instead a misperception of the gender gap ten years after graduation because students expect the gender gap to be roughly constant while realizations point toward an increasing gap with tenure. The gender gap diminishes but does not disappear when several controls such as family background, place of birth, high school diploma, university program attended, performance at university, civil status and number of children are taken into account.

A second set of intriguing results concerns the evidence on realized gender gaps independently of expectations. Here, in contrast with the recent literature for industrialized countries, we see no evidence of a diminishing gender gap between subsequent cohorts of Bocconi graduates at the beginning of a career. In particular, the gender gap immediately after graduation displays a puzzling upward trend and reaches particularly high and significant values in the most recent 1997 cohort. This result is likely to be a consequence of the elimination of the cost of living asdjustment scheme called Scala Mobile which prevailed in Italy during the '80s and was abolished in 1992.

Finally, while the gender wage gap for the best graduates is large already at the beginning of a career but remains more or less constant throughout the working life, for the worse graduates the gender gap starts slightly lower but increases more significantly with experience. These results suggest that the careers of females are characterized by "glass ceilings" in particular at high skill levels, and by "sticky floors" at the opposite end of the skill spectrum. Unfortunately, our data do not allow to shed more light on the real nature and on the determinants of these differences in career developments.

The existence of gender differences of this kind, even in a very homogeneous group of high skilled workers like the one constituted by Bocconi graduates, is striking and clearly calls for more research and better data. 


\section{References}

Arrow K.J., 1973, The Theory of Discrimination" in Discrimination in Labor Markets, ed. by O. Ashenfelter and A. Rees. Princeton: Princeton University Press, 3-33.

Becker G.S., 1957, The Economics of Discrimination, Chicago: University of Chicago Press.

Blau, F.D. and L.M. Kahn, 1996, Wage Structure and Gender Earnings Differentials: an International Comparison, Economica, 63, S29-S62.

Blau, F.D. and L.M. Kahn, 1997, Swimming Upstream: Trends in the Gender Wage differential in the 1980s, Journal of Labor Economics, 15, 1-42.

Blundell R., Gosling A., Ichimura H. and C. Meghir, 2002, Changes in the Distribution of Male and Female Wages Accounting for Employment Composition, mimeo.

Booth A.L., M. Francesconi and J. Frank, 1998, Glass Ceilings or Sticky Floors?, CEPR Discussion Paper 1965.

Brunello G., Lucifora C. and R. Winter-Ebmer, 2001, The Wage Expectations of European College Students, mimeo.

Datta Gupta N., Oaxaca R.L. and N. Smith, 2001, Swimming Upstream, Floating Downstream: Trends in the U.S. and Danish Gender Wage Gap, CLS Working Papers, 01-6.

Erickson C., and A. Ichino, 1994, Wage Differentials in Italy: Market Forces, Institutions and Inflation, in: Differences and Changes in the Wage Structure, Richard Freeman, and Larry Katz, eds. (Chicago, IL: NBER and University of Chicago Press).

Filippin A., 2002, Discrimination and Workers' Expectations, EUI, mimeo.

Fitzenberger, B. and G. Wunderlich, 2002, The Changing Gender Gap Across the Wage Distribution in the U.K., mimeo.

Flabbi L., 1997, Gender discrimination and Return to Education: Estimations on Individual Data, Rivista di Politica Economica, 12.

Kunze A., 2002, Gender Differences in Entry Wages and Early Career Wages, IZA Working Paper n. 626 
Light A. and M. Ureta, 1995, Early-Career Work Experience and Gender Wage Differentials, Journal of Labor Economics, 13:1, 121-154.

Loprest P.J., 1992, Gender Differences in Wage Growth and Job Mobility, American Economic Review, 82:2, 526-532. 
Table 1: Classes of income in the questionnaires

\begin{tabular}{ll}
\hline \hline & up to 1032.91 \\
from 1032.91 & up to 2065.83 \\
from 2065.83 & up to 3098.74 \\
from 3098.74 & up to 4131.66 \\
from 4131.66 & up to 5164.57 \\
from 5164.57 & \\
\hline \hline
\end{tabular}

Note: Monthly income net of taxes and contributions at 2001 prices (Euro).

Table 2: Percentage gender wage gap - uncontrolled

\begin{tabular}{lccccc}
\hline \hline Cohort: & Students & grad85 & grad89 & grad93 & $\operatorname{grad} 97$ \\
N. obs: & 887 & 234 & 469 & 637 & 765 \\
\hline$t_{0}$ & $-0.097^{* * *}$ & -0.024 & -0.030 & $-0.063^{* *}$ & $-0.096^{* * *}$ \\
& $(0.027)$ & $(0.053)$ & $(0.032)$ & $(0.029)$ & $(0.026)$ \\
\hline$t_{1}$ & $-0.139^{* * *}$ & $-0.569^{* * *}$ & $-0.423^{* * *}$ & $-0.263^{* * *}$ & $-0.158^{* * *}$ \\
& $(0.026)$ & $(0.068)$ & $(0.048)$ & $(0.037)$ & $(0.030)$ \\
\hline \hline
\end{tabular}

Note: standard errors in parentheses with $\mathrm{p}<0.1=^{*}, \mathrm{p}<0.05={ }^{* *}, \mathrm{p}<0.01={ }^{* * *}$. The column labels "grad**" indicate the $19^{* *}$ cohort of graduates.

$t_{0}=$ students' expected wage 1 year after graduation; 1 st wage earned by graduates $t_{1}=$ students' expected wage 10 years after graduation; graduates' current wage Percentage gap computed on real wages (prices in 2001). 
Table 3: Percentage gender wage gap - controlled

\begin{tabular}{lccccc}
\hline \hline Cohort: & Students & grad85 & grad89 & grad93 & grad97 \\
N. obs: & 887 & 234 & 469 & 637 & 765 \\
\hline$t_{0}$ & $-0.082^{* * *}$ & -0.009 & -0.020 & -0.064 & $-0.125^{* * *}$ \\
& $(0.027)$ & $(0.121)$ & $(0.064)$ & $(0.044)$ & $(0.029)$ \\
\hline$t_{1}$ & $-0.106^{* * *}$ & $-0.308^{* *}$ & $-0.150^{*}$ & $-0.185^{* * *}$ & $-0.162^{* * *}$ \\
& $(0.026)$ & $(0.155)$ & $(0.092)$ & $(0.056)$ & $(0.033)$ \\
\hline \hline
\end{tabular}

Note: standard errors in parentheses with $\mathrm{p}<0.1=^{*}, \mathrm{p}<0.05=* *, \mathrm{p}<0.01=* * *$. Controls: high school diploma, family background, household business, degree program, place of birth, performance at university, civil status and number of children. For graduates, also part-time work is used as control.

The column labels "grad**" indicate the $19^{* *}$ cohort of graduates.

$t_{0}=$ students' expected wage 1 year after graduation; 1 st wage earned by graduates $t_{1}=$ students' expected wage 10 years after graduation; graduates' current wage Percentage gap computed on real wages (prices in 2001).

Table 4: Annual growth of the gender wage gap

\begin{tabular}{lccccc}
\hline \hline Cohort: & Students & grad85 & grad89 & grad93 & grad97 \\
N. obs: & 887 & 234 & 469 & 637 & 765 \\
\hline uncontrolled & $-0.017^{*}$ & $-0.081^{* * *}$ & $-0.079^{* * *}$ & $-0.064^{* * *}$ & $-0.049^{* * *}$ \\
& $(0.010)$ & $(0.020)$ & $(0.014)$ & $(0.013)$ & $(0.017)$ \\
\hline controlled & -0.011 & -0.054 & -0.033 & $-0.038^{*}$ & $-0.036^{*}$ \\
& $(0.010)$ & $(0.041)$ & $(0.027)$ & $(0.021)$ & $(0.020)$ \\
\hline \hline
\end{tabular}

Note: standard errors in parentheses with $\mathrm{p}<0.1={ }^{*}, \mathrm{p}<0.05={ }^{* *}, \mathrm{p}<0.01={ }^{* * *}$ Controls: family background, place of birth, high school diploma, university program attended, performance at university, civil status and number of children. For graduates, also part-time work is used as control. The column labels "grad**" indicate the $19^{* *}$ cohort of graduates. 
Table 5: Grades defining top and bottom $25 \%$ performance in the population of graduates

\begin{tabular}{ccc}
\hline \hline cohort & bottom 25\% & top 25\% \\
1985 & $<24.37$ & $>27.15$ \\
1989 & $<24.45$ & $>27.12$ \\
1993 & $<25.20$ & $>27.82$ \\
1997 & $<25.72$ & $>27.89$ \\
\hline \hline
\end{tabular}

Note: the support of the grade variable is $[18,30]$

Table 6: Normalised indicator defining top and bottom $25 \%$ performance in the population of students

\begin{tabular}{ccc}
\hline \hline Students & bottom 25\% & top 25\% \\
2nd year & $<38.93$ & $>60.36$ \\
\hline \hline
\end{tabular}

Note: the support of the performance variable is $[0,100]$

Table 7: Distribution of "top" and "bottom" in the sample

\begin{tabular}{ccc}
\hline \hline Group & \% of "top" & \% of "bottom" \\
Cohort 85 & 17.95 & 27.35 \\
Cohort 89 & 21.11 & 24.31 \\
Cohort 93 & 21.19 & 25.75 \\
Cohort 97 & 23.01 & 24.71 \\
2nd yr stud & 34.22 & 12.86 \\
\hline \hline
\end{tabular}


Table 8: Expected and realized gender gap one year after graduation, by educational performance and controlling for observable characteristics

\begin{tabular}{lcccccc}
\hline \hline & top & top & medium & medium & bottom & bottom \\
& Stud. & Grad. & Stud. & Grad. & Stud. & Grad. \\
N. obs: & 288 & 452 & 466 & 1122 & 133 & 531 \\
\hline Female & -0.038 & $-0.165^{* * *}$ & $-0.087^{* *}$ & $-0.119^{* * *}$ & $-0.134^{*}$ & $-0.138^{* * *}$ \\
& $(0.048)$ & $(0.053)$ & $(0.037)$ & $(0.029)$ & $(0.076)$ & $(0.050)$ \\
\hline \hline
\end{tabular}

Note: standard errors in parentheses with $\mathrm{p}<0.1=^{*}, \mathrm{p}<0.05={ }^{* *}, \mathrm{p}<0.01={ }^{* * *}$. Dependent variable: log of real wage.

Controls: family background, place of birth, high school diploma, university program attended, civil status and number of children. For graduates, also time since graduation and part-time work are used as control.

Table 9: Expected and realized gender gap growth, by educational performance and controlling for observable characteristics

\begin{tabular}{lcccccc}
\hline \hline & top & top & medium & medium & bottom & bottom \\
& Stud. & Grad. & Stud. & Grad. & Stud. & Grad. \\
N. obs: & 288 & 452 & 466 & 1122 & 133 & 531 \\
\hline Female & -0.008 & -0.008 & -0.002 & $-0.016^{*}$ & 0.005 & $-0.041^{* * *}$ \\
& $(0.005)$ & $(0.016)$ & $(0.004)$ & $(0.009)$ & $(0.008)$ & $(0.015)$ \\
\hline \hline
\end{tabular}

Note: standard errors in parentheses with $\mathrm{p}<0.1=^{*}, \mathrm{p}<0.05=^{* *}, \mathrm{p}<0.01={ }^{* * *}$. Dependent variable: real wage growth.

Controls: family background, place of birth, high school diploma, university program attended, civil status and number of children. For graduates, also time since graduation and part-time work are used as control. 


\section{Occupation and income expectations of Bocconi students}

Dear Student, we kindly ask you to fill this questionnaire concerning entrance in the labor market. Please consider that data are collected for the sole purpose of scientific research and that results will be circulated referring to aggregate statistics only.

1. After graduation do you expect to work in a household business? $\square$ YES $\square$ NO

2. Your occupation will more likely be: Paid Employment

White collar....

Middle manager.

General manager

Secondary school teacher

University teacher....

Other paid employment (GIVE DETAILS)

Self Employment

Business consultant.

Professional (non business consultant).

Enterpreneur.

Other self employment (GIVE DETAILS)

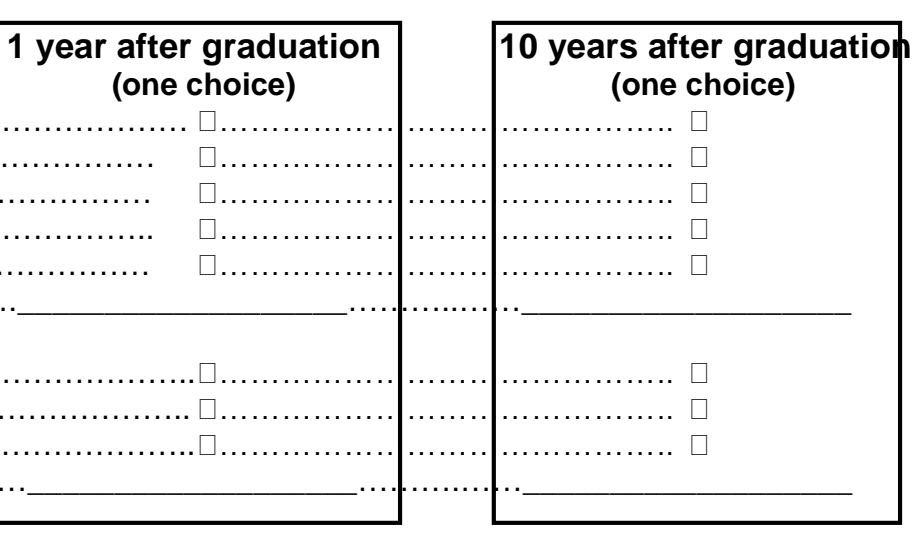

3. In which sector? (one choice)

$\square$ manufacturing $\quad \square$ finance $\quad \square$ public $\quad \square$ trade $\quad \square$ other (GIVE DETAILS)

4. How much do you think your monthly labour income net of taxes and contributions will be (at constant prices)

Less than L. 2.000.000.

L.2.001.000 - L.3.000.000....

L.3.001.000 - L.4.000.000.

L.4.001.000 - L.5.000.000.

L.5.001.000 - L.6.000.000.

L.6.001.000 - L.8.000.000.

L.8.001.000 - L.10.000.000

More than L. 10.000.000.

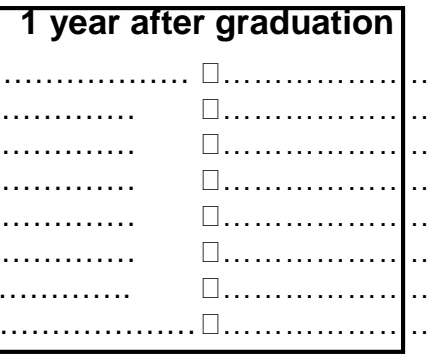

10 years after graduation

5. Setting to $\mathbf{1 0 0}$ your wage 1 year after graduation, how much do you think would be earned by a student with the same characteristics as yours but of the other gender?

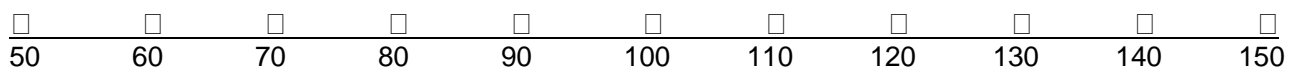

6. Setting to $\mathbf{1 0 0}$ your wage $\mathbf{1 0}$ year after graduation, how much do you think would be earned by a student with the same characteristics as yours but of the other gender?

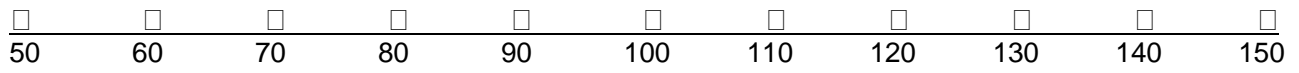

7. If your answer in $\mathbf{5}$ and/or 6 was different from 100: why? (multiple choices allowed)

$\square$ Characteristics and aptitudes actually differ between males and females

$\square$ Different distribution of household duties

$\square$ Employers expect differenct characteristics between males and females

$\square$ Employers' tastes given equal characteristics and hosehold duties

8. Year

9. Degree Program

10. Province of birth

11. Gender

12. Date of birth

13. Nr. of passed exams

14. Average grade

15. Education of the father

16. Education of the mother

17. Father's occupation

18. Mother's occupation

19. Tuition category $\square 2^{\wedge} \quad \square 3^{\wedge} \quad \square 4^{\wedge} \quad \square$ F.C.

$\square$ CLE $\square$ CLEA $\square$ CLAPI $\square$ CLELI $\square$ CLG $\square$ CLEFIN $\square$ CLEACC

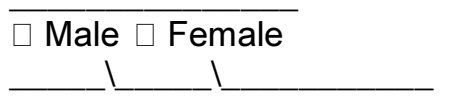

\begin{tabular}{llll}
\hline$\square$ PRIMARY & $\square$ SECONDARY & $\square$ COLLEGE & $\square$ UNIVERSITY \\
$\square$ PRIMARY & $\square$ SECONDARY & $\square$ COLLEGE & $\square$ UNIVERSITY
\end{tabular}

$\square 1^{\wedge}$ 


\section{IZA Discussion Papers}

\begin{tabular}{|c|c|c|c|c|}
\hline No. & Author(s) & Title & Area & Date \\
\hline 811 & $\begin{array}{l}\text { M. Corak } \\
\text { W.-H. Chen }\end{array}$ & $\begin{array}{l}\text { Firms, Industries, and Unemployment Insurance: } \\
\text { An Analysis Using Employer-Employee Data }\end{array}$ & 1 & 06/03 \\
\hline 812 & $\begin{array}{l}\text { J. T. Addison } \\
\text { T. Schank } \\
\text { C. Schnabel } \\
\text { J. Wagner }\end{array}$ & $\begin{array}{l}\text { German Works Councils in the Production } \\
\text { Process }\end{array}$ & 3 & $06 / 03$ \\
\hline 813 & E. P. Lazear & $\begin{array}{l}\text { Firm-Specific Human Capital: A Skill-Weights } \\
\text { Approach }\end{array}$ & 5 & $06 / 03$ \\
\hline 814 & $\begin{array}{l}\text { G. Ridder } \\
\text { G. J. van den Berg }\end{array}$ & $\begin{array}{l}\text { Measuring Labor Market Frictions: A Cross- } \\
\text { Country Comparison }\end{array}$ & 6 & $07 / 03$ \\
\hline 815 & $\begin{array}{l}\text { A. Aakvik } \\
\text { K. G. Salvanes } \\
\text { K. Vaage }\end{array}$ & $\begin{array}{l}\text { Measuring Heterogeneity in the Returns to } \\
\text { Education in Norway Using Educational Reforms }\end{array}$ & 6 & $07 / 03$ \\
\hline 816 & $\begin{array}{l}\text { T. T. Herbertsson } \\
\text { J. M. Orszag }\end{array}$ & $\begin{array}{l}\text { The Early Retirement Burden: Assessing the } \\
\text { Costs of the Continued Prevalence of Early } \\
\text { Retirement in OECD Countries }\end{array}$ & 3 & $07 / 03$ \\
\hline 817 & $\begin{array}{l}\text { T. M. Andersen } \\
\text { T. T. Herbertsson }\end{array}$ & Measuring Globalization & 2 & $07 / 03$ \\
\hline 818 & J. Pencavel & The Surprising Retreat of Union Britain & 3 & $07 / 03$ \\
\hline 819 & $\begin{array}{l}\text { M. Beine } \\
\text { F. Docquier } \\
\text { H. Rapoport }\end{array}$ & $\begin{array}{l}\text { Brain Drain and LDCs' Growth: Winners and } \\
\text { Losers }\end{array}$ & 1 & $07 / 03$ \\
\hline 820 & $\begin{array}{l}\text { C. M. Cornwell } \\
\text { K. H. Lee } \\
\text { D. B. Mustard }\end{array}$ & $\begin{array}{l}\text { The Effects of Merit-Based Financial Aid on } \\
\text { Course Enrollment, Withdrawal and Completion } \\
\text { in College }\end{array}$ & 6 & $07 / 03$ \\
\hline 821 & $\begin{array}{l}\text { P. Carneiro } \\
\text { J. J. Heckman }\end{array}$ & Human Capital Policy & 6 & $07 / 03$ \\
\hline 822 & $\begin{array}{l}\text { D. Weichselbaumer } \\
\text { R. Winter-Ebmer }\end{array}$ & $\begin{array}{l}\text { The Effects of Competition and Equal Treatment } \\
\text { Laws on the Gender Wage Differential }\end{array}$ & 6 & $07 / 03$ \\
\hline 823 & A. Filippin & Discrimination and Workers' Expectations & 5 & $07 / 03$ \\
\hline 824 & A. Filippin & $\begin{array}{l}\text { Discrimination and Workers' Expectations: } \\
\text { Experimental Evidence }\end{array}$ & 5 & $07 / 03$ \\
\hline 825 & $\begin{array}{l}\text { A. Filippin } \\
\text { A. Ichino }\end{array}$ & $\begin{array}{l}\text { Gender Wage Gap in Expectations and } \\
\text { Realizations }\end{array}$ & 5 & $07 / 03$ \\
\hline
\end{tabular}

An updated list of IZA Discussion Papers is available on the center's homepage www.iza.org. 